Khalife, S., Hamzeh, F. (2019). "A Framework for Understanding the Dynamic Nature of Value in Design and Construction" In: Proc. $27^{\text {th }}$ Annual Conference of the International. Group for Lean Construction (IGLC), Pasquire C. and Hamzeh F.R. (ed.), Dublin, Ireland, pp. 617-628. DOI: https://doi.org/10.24928/2019/0254. Available at: 〈www.iglc.net>.

\title{
A FRAMEWORK FOR UNDERSTANDING THE DYNAMIC NATURE OF VALUE IN DESIGN AND CONSTRUCTION
}

\author{
Salam Khalife ${ }^{1}$ and Farook Hamzeh ${ }^{2}$
}

\begin{abstract}
Since the introduction of the Transformation, Flow, and Value (TFV) theory, the lean construction community has widely invested in research to understand and analyse effectively the concept of value in design and construction. Researchers looked into different contexts, mainly into manufacturing, marketing and business, where the concept of perceived value and value creation has been comprehensively studied. The main driver is that delivering value is regarded as an economic advantage and a pivotal aspect in those industries. Accordingly, researchers used these concepts to reflect on their applicability and compatibility within the construction industry. However, scrutinizing the body of knowledge addressing value in construction, one can notice the wide-ranging and scattered concepts concerning value. This paper thus aims at exploring and assembling the different attributes influencing value in construction. A review and analysis of literature is conducted, mainly in the proceedings of the IGLC conference. An integration framework structuring the multi attributes is then presented focusing on the dynamic nature of value. The overall objective is to identify the research trends concerned with value in construction and specify the probable gaps in knowledge as well as suggesting areas that need further investigation. The research presented in this paper is a first step towards understanding the different dimensions of value and building a unified platform for future research endeavours.
\end{abstract}

\section{KEYWORDS}

Value, collaboration, value generation, stakeholders, value management.

\section{INTRODUCTION}

Delivering value in projects has been a major concern in the construction industry. The global competition in the economy and the market imposed a need to find new ways to gain competitive advantage, one of which is achieving a superior customer value delivery (Woodruff 1997). The building industry had always focused on achieving value for the ultimate customer, representing the paying customer or the client (Womack and Jones

1 PhD student, Department of Civil and Environmental Engineering, American University of Beirut, P.O. Box 11-0236, Riad El-Solh, Beirut, Lebanon 1107 2020; email: sgk19@ mail.aub.edu

2 Associate Professor, Civil and Environmental Engineering Dept., University of Alberta, Canada, hamzeh@ualberta.ca 
1996). In fact, the value concept was predominantly related to attaining customer's requirements. However, researchers and practitioners realized the need to involve the end customer or the user in construction projects. Soon after, a shift towards involving other stakeholders in the supply chain was established, and researchers emphasized the importance of having a multidisciplinary stakeholders approach to maximize value delivery (Emmitt et al. 2005). In the lean approach, similar emphasis is expressed regarding the idea of maximizing value to different customers, the purchasers, users, and producers, representing the entities who deliver the system (Ballard et al. 2001). With recent trends towards sustainability, the customer notion was even more extended to include the society as a whole, and thus social aspects became important considerations in value delivery (Salvatierra-Garrido and Pasquire 2011).

Despite the necessity of recognizing the needs of different involved stakeholders, a number of hurdles stand in the way of achieving maximum project value along with aligning the different needs. Stakeholders come with different values and backgrounds which dramatically complicate the process of construction and lead to conflicts on projects (Fenn et al. 1997). Additionally, the major struggle in the construction industry is understanding project value and its generation throughout the project phases. Koskela (1996) admitted that it is theoretically and conceptually hard to understand value generation during projects. Value is seen as an ambiguous term and it is still not well communicated (Salvatierra-Garrido et al. 2012). Moreover, value conflicts are found to be high in construction organizations leading to low commitment from internal stakeholders (Panahi et al. 2017).

Having acknowledged the fact that value generation and enhancement is problematic on construction projects, researchers invested a great effort in understanding the theoretical concept of value including: what is value? (Emmitt et al. 2005), what are the characteristics of value? (Drevland et al. 2018), is value for all stakeholders of equal importance? (Drevland and Tillmann 2018), etc.

The literature is found to be diverse in connection with value concepts and complications. This paper is at the level of diagnosis to understand the dynamic nature of value. It does not intend to provide an extensive review of literature on the specific concepts of value neither to provide the solutions for value enhancement discussed elsewhere. Instead, the framework presented in this paper aims at paving the road for a better perception of the different factors that affect value in design and construction. Additionally, the authors aim to comprehend the different attributes and the different models presented in the body of knowledge. The research presented in this paper is a primary step towards a more in depth analysis of value through linking the ideas in one coherent framework.

The research aims at answering the following two questions:

- What are the main research streams discussing value in construction projects?

- How can the identified factors be envisioned together and in relation to one another?

\section{METHODOLOGY AND RESEARCH SCOPE}

The research presented in this paper is based on a literature review study to generate a unified framework mapping the existing literature. The following steps were pursued: (1) 
collecting references from the IGLC conference papers and other google scholar papers from the fields of construction as well as fields of marketing and business discussing customers value and concepts related to value generation and enhancement, (2) exploring and scrutinizing the papers and identifying the diverse topics included, (3) categorizing the references according to the topics and keywords identified, (4) developing the framework based on the identified subjects, and (5) making sense of the mapped topics and the framework by adding the different related dimensions in a logical manner based on the overall readings and on the experience of the authors in the construction industry.

The research scope is limited to establishing the framework for future research encounters on topics about value and the factors influencing value enhancement on projects. The authors believe there are many studies tackling the subject at hand, yet the authors couldn't have cited all of these studies. Nevertheless, the authors argue that the framework is all inclusive of those factors and topics related to value. Yet, they are open to the fact that the research does not stop at a certain point in time, and that probable future dimensions shall be explored; otherwise, there is no point of having this frame work as a first step to future research endeavours.

\section{LITERATURE REVIEW}

\section{VALUE THEORY}

The greatest concern regarding value in any industry is understanding its nature and its characteristics. However, the discussion of value creation is rather old, where it has been debated for 2000 years in different domains and through different interpretations $(\mathrm{Ng}$ and Smith 2012).

Value, within the construction project's setting, is often defined as the understanding and achievement of the client's needs or the client's objectives (Bertelsen and Emmitt 2005). Project success is thus evaluated based on these objectives, which were traditionally connected to three main factors: cost, time and quality (Ward et al. 1991). The term 'value' should be distinguished from 'values'. On the one hand, values represent the beliefs, morals, standards and rules that are reflected in the attitude and behavior of individuals; additionally, values influence the individual's assessment of products and services (Thomson et al. 2003). On the other hand, value is the result of an 'evaluative judgement' where values represent the basis for such judgement (Sánchez-Fernández and IniestaBonillo 2007). Therefore, values frame the assessment of value.

In a project's context, the design and construction involve multiple stakeholders and parties: clients, designers, builders, end-users, operators, etc. Researchers studied an extended list of stakeholders on projects. These were categorized into three entities: responsible stakeholder, impacted stakeholder, and interested stakeholder (Zhang and ElGohary 2016). Each involved party conveys different interests and needs. Although the focus in construction projects is primarily on achieving the owner's and user's objectives, as it is the case in most studies, the fact that every involved stakeholder has his/her own interests and needs, thus formulating a different value perception, cannot be overlooked (Haddadi et al. 2016). In fact, the discussion and agreement of value parameters is 
"fundamental to the achievement of improved productivity and client/user satisfaction" (Emmitt et al. 2005).

Accordingly, project value is the result of negotiated and shared guiding principles to which all stakeholders shall subscribe (Thomson et al. 2003). Irrespective of the parties' own perception of value at the onset of the project, it is important that stakeholders have a common ground and mutual understanding to what the Project Value is; this shall be established through effective communication and collaboration. "When individuals collaborate to realize a common goal, projects are formed. A value system can emerge if values are expressed and shared between them" (Thomson et al. 2003).

Having to agree on a common perspective of what the project value constitutes is explicitly faced with hurdles concerning: communication, the willingness to compromise, and the position or authority of different stakeholders. Yet, another characteristic that brings more complications to the projects is that value is dynamic and evolutionary in nature as it tends to change over time (Emmitt et al. 2004; Sánchez-Fernández and IniestaBonillo 2007). Clients, in general, do not know their full desires and needs at the onset of the project. It is the duty of the designers to guide and collaborate with clients to reveal the full requirements through creative workshops and innovative techniques. Previously, Ballard and Howell (1998) stressed on the role of the designer to clarify the effects of customer's desires (means), which could make an influence on their goals.

Throughout the conceptual and design development phases of projects, designers themselves evolve in their thinking based on the proliferation of more information from across disciplines. As such, the project value perceived would not remain constant. Value co-creation is the term used for expressing the interactive process between the service provider and the customer in order to create value collaboratively (Rozenes and Cohen 2017). Accordingly, several authors suggested having periodic workshops that encompass the developing value perceptions, with an aim to grasp and detect any potential changes needed based on these evolved perceptions (Emmitt et al. 2004).

\section{STAKEHOLDERS THEORY}

In an attempt to recognize and understand the stakeholders' influence on value perceptions and project success, researchers investigated in theories within marketing and management related to stakeholders. Donaldson and Preston (1995) elaborated on the stakeholders theory stressing on its core concept which is acknowledging the fact that each stakeholder has 'diverse interests', thus, it is a moral obligation to have a "mutually supportive framework".

Stakeholders are said to have hidden 'reservoirs of power' that they exercise during their interactions within the social network (Bourne and Walker 2005). Accordingly, identifying and managing stakeholders relationships while visualizing their influence through helpful tools, such as the "stakeholder circle" presented by Bourne and Walker (2005), would provide effective ways to enhance project success. Stakeholders' engagement on projects is crucial, and managing their relation and engagement is even more vital that researchers have suggested several methods to address this engagement through project management approaches (Cleland and Ireland 2002). Olander (2007) introduced the 'stakeholders impact index' for studying stakeholders' influence for better 
project management practices. Additionally, multiple critical success factors (CSF) for stakeholders management were introduced and tested on projects; on top of these listed CSFs comes "managing stakeholders with social responsibilities" and "assessing stakeholders' needs and constraints" (Yang et al. 2009). Those social responsibilities include economic, legal, ethical and environmental considerations that are said to be preconditions for stakeholders management (Yang et al. 2009).

\section{VALUE GENERATION AND ENHANCEMENT MODELS}

"Value is generated through a process of negotiation between customer ends and means" according to Ballard and Howell (1998). Several studies proposed frameworks and models for implementation in an attempt to enhance value on projects during design and construction (Haddadi et al. 2016; Haddadi et al. 2017; Thyssen et al. 2010). Mainly, those models are in connection with approaches such as value engineering (Kelly and Male 2003), value management (Musa et al. 2016), and value-based management (Wandahl and Bejder 2003). Lean principles are at the heart of several models which elaborated on approaches such as target value design, lean project delivery system LPDS, and set-based design (Miron et al. 2015; Tillmann et al. 2013). Other researchers looked into the power of Building Information modelling (BIM) and collaborative approaches in enhancing value on projects (Park et al. 2017). Additionally, conceptual models are developed to augment value co-creation such as the one suggested by Heredia Rojas et al. (2018).

Stakeholder Value Network (SVN) is a method developed to analyse value delivery through computing stakeholders' influence within a network. SVN is used in different domains mainly in engineering systems (Cameron 2007). Feng (2013) used SVN to explore the links between stakeholders in large engineering projects. Zheng et al. (2019) employed the SVN technique to study value flows in BIM based projects.

While the presence of plentiful models and proposed frameworks helped in better understanding stakeholder's value, the aim of maximizing value generation in a project's setting is still an open and debatable topic that needs further investigations. A starting point is understanding the different attributes collectively by mapping them together under one framework.

\section{A MULTI-ATTRIBUTE INTEGRATION FRAMEWORK}

The current study explored the literature for concepts related to value and factors within projects that have a direct and indirect influence on value perceptions. The collected information resulted in a set of categories that interrelate with each other and constitute what the authors called a multi-attribute integration framework. The framework is presented in Figure 1. A conceptual framework is "an interconnected set of ideas (theories) about how a particular phenomenon functions or is related to its parts. The framework serves as the basis for understanding the causal or correlational patterns of interconnections across events, ideas, observations, concepts, knowledge, interpretations and other components of experience" (Svinicki 2010), p.5. The framework, developed as per the previously mentioned principles, is considered a visual mapping for the broad topics interfering with value perceptions, generation, and enhancement. In what follows, a 
thorough explanation of the broad keywords and topics covered in the framework is presented.

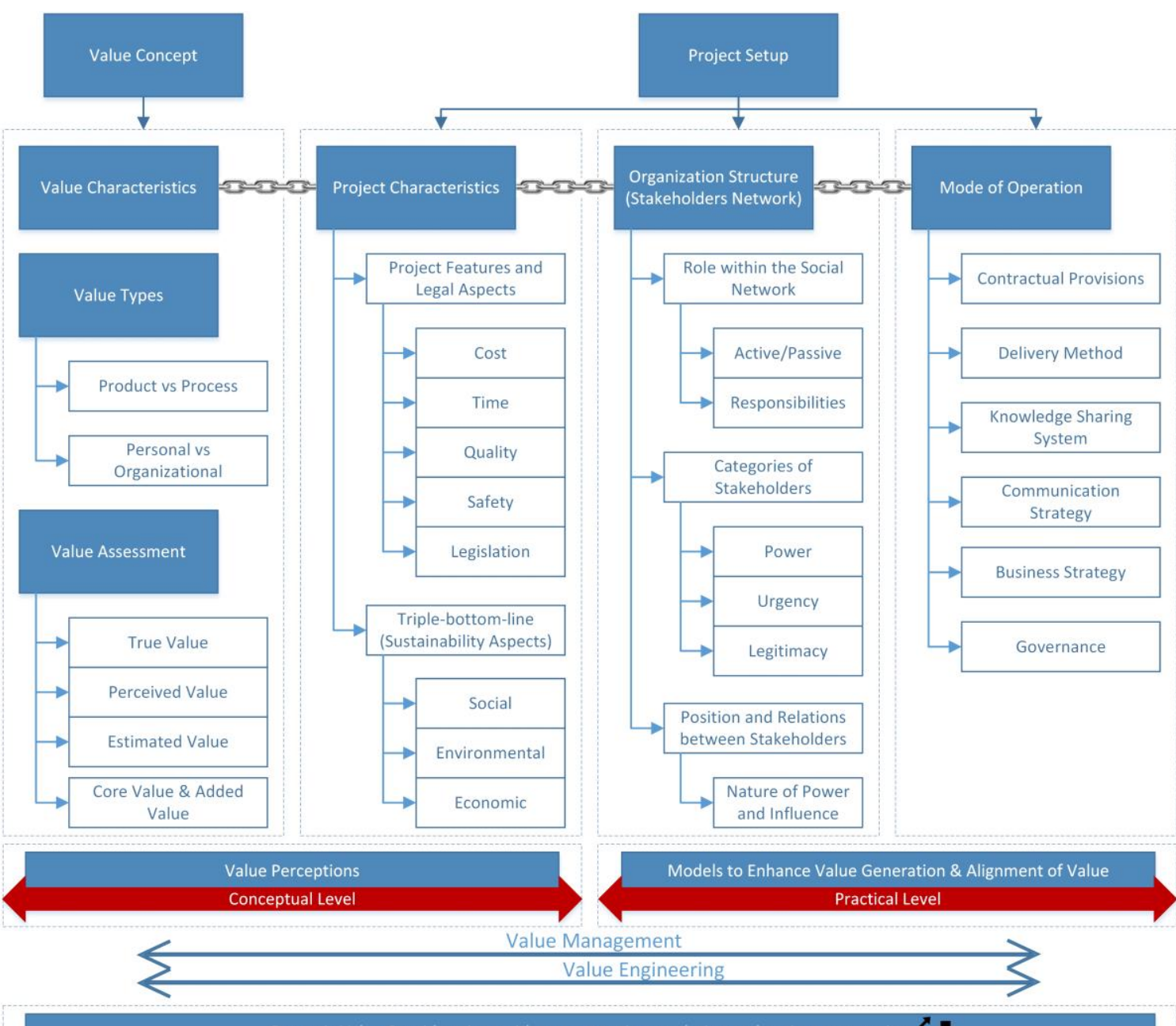

Dynamic Value Considerations with respect to time evolution and project progression

Figure 1. Multi-attribute integration framework

The synthesis of the encountered topics on value resulted in identifying two major headings in the integration framework: the Value Concept and the Project Setup. Basically, the two headlines are inseparable, where value concepts are usually observed in the corresponding project setup; however, the purpose here is to reflect on the research streams where some studies have discussed concepts related to value irrespective of the project setting or specifications. Yet, more often than not, researchers were eager to further understand the correlations of different attributes stemming from these major areas. The multi-tier attributes under each main heading are explained hereafter. 


\section{A. THE VALUE CONCEPT}

Understanding the value concept is an essential step towards controlling and managing its impact on the project outcome. The outcome of design as well as the outcome of construction, or the product itself, is contingent upon the perceived value between the different players involved in those phases and the encompassed processes (Kelly et al. 1993).

Based on the literature, the value concept is discussed from three perspectives: characteristics, types, and assessment. First, the research delves into recording Value Characteristics which is observed to be a hot topic and a path to understand the 'ambiguous' concept (Barima 2010). Thyssen et al. (2010) identified several characteristics describing value within the construction industry based on their literature exploration. Value is argued to be (1) a subjective judgement due to the interference of human personal interest, (2) an objective measurement when considering and comparing alternatives as to which is more valuable, (3) a context-dependent matter, (4) a dynamic issue as it changes over time, (5) information-dependent, and (6) instrumental for projects (Thyssen et al. 2010). Drevland et al. (2018) built on previous interpretations of value characteristics and defined nine tenets to decompose this complex term. They stressed on the fact that value is a result of an evaluative judgement with its factors being evaluated simultaneously. Thus, consequences are not summative, and value is not linear. Value consequences are expressed in the gained or lost experience of the different stakeholders.

Second, researchers examined Value Types in construction projects, and the most common terminology found is differentiating between product value and process value. Emmitt et al. (2005) elaborated on the difference between the two terms. Process value represents both soft values (e.g. resolving conflicts, better communication) and hard values (e.g. adhering to budget and time requirements) that are associated with clients' experience during the delivery of the project by the team. Product value represents the built facility or the project with respect to firmness, commodity, and delight, or the Vitruvian values (Emmitt et al. 2005). These are related to Project Characteristics explained under the project setup. Other types of value include personal vs. organizational value, where perceived value shall be considered both at the personal level and at the organizational commitment level (Panahi et al. 2017).

The third aspect deduced from different studies regarding the value concept is Value Assessment. Value on projects need to be evaluated so that management practices could take place effectively. Drevland et al. (2018) differentiated between true value, perceived value, and estimated value. Perceived value is dependent on the perceiver's knowledge and values, while true value is achieved when the perceiver has perfect knowledge. The estimated value is recorded by someone else, the estimator, to suspect about the value perception of others based on the knowledge at hand and within its context. Additionally, researchers designated two other types of value on projects: the core value and the added value (Salem Khalifa 2004). Understanding these different assessments would help multidisciplinary teams and involved stakeholders to establish a common ground to assess the overall project value. Nevertheless, these are only labels for value and actions need to be taken based on factors within the project setting. 


\section{B. THE PROJECT SETUP}

In addition to value concepts, value is debated in the literature within the project setup. To understand the project setup or the environment and the different players, three main categories need to be assessed: Project Characteristics, Organization Structure, and the Mode of Operation.

Project Characteristics are associated with the project features that are normally set at the beginning of every project. Cost (budget), time (duration), and quality (specifications), designated as the iron triangle in literature, are the basic features in every project. Other characteristics, such safety and legal issues shall be included as they normally affect project value. Further considerations featuring value in projects are the sustainability measures comprising the social, economic, and environmental aspects (Novak 2012). With the current global environmental problems, sustainability measures are instrumental to project value.

Organization Structure is a fundamental category that reflects on the stakeholders' important role in value creation and enhancement. Not all stakeholders take an active role in the project to maximize value and some are passive recipients of value, whether it is positive or negative (Drevland et al. 2017). The type of responsibilities carried by each involved party in the project setting is an additional attribute affecting the overall project value. Earlier, Mitchell et al. (1997) categorized stakeholders based on three attributes: Power, Urgency, and Legitimacy. Haddadi et al. (2016) focused on the major facet which is power. The position and relation between stakeholders is attributed to the nature of power they hold and thus the influence on other stakeholders.

The Mode of Operation is the third core aspect that has a direct effect on enhancing value generation on projects. The delivery method, the contractual provisions, and the knowledge sharing system are basic drivers when it comes to value delivery. Matthews and Howell (2005) explain the difficulties in maximizing value on projects that are restricted with a type of contract that impedes coordination and instead rewards individuals on optimizing their performance at the expense of others. Therefore, the call for integration in project delivery and implementing relational contracting have shown positive trends towards aligning stakeholders interests (Forbes and Ahmed 2010). Likewise, strategies describing the mode of operation on projects, such as communication strategies, business strategies, and governance are interesting attributes to be studied in connection with value on construction projects. Some also have suggested integrated governance to augment value generation (Tillmann et al. 2012). Other researchers have tested the use of Building Information Modeling BIM on fostering collaboration to enhance project value as described earlier in the literature section.

The set of models found in the literature tackling issues of generating and maximizing value on projects address the practical level and relate to the organization structure and the mode of operation. On the contrary, value perceptions work on the conceptual level and thus relate to the value concept and the project characteristics. Value management and value engineering practices are also associated with the mentioned attributes but do not necessarily include all the needed strategies to enhance project value. Other gaps are found 
in the process of being able to measure and evaluate project value as a basis for a control mechanism aimed at value enhancement on the practical level.

\section{TIME PROGRESSION AND VALUE EVOLUTION}

The aforementioned factors and attributes are not constant as any of those listed attributes in the framework might change with time. Therefore, there is a need to emphasize on the dynamic nature of value.

Nonetheless, the authors need to stress on the fact that all categories are interrelated. Hence, the value concept and the three main categories of the project setup are subcategories of one another as represented in Figure 2. This also emphasizes on the dynamic nature that project value entails. Therefore, any potential change in any of the categories would affect other factors in other categories, such as changing the knowledge sharing system or coordination strategies would have a direct effect on stakeholders' relations and, subsequently, value perceptions.

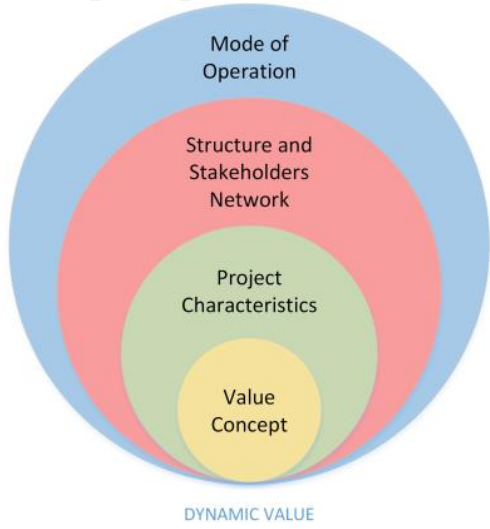

Figure 2. The integration between value related aspects rendering value as dynamic

The fact that construction projects are complex in their nature is well established within the management literature. A further dimension is added which is qualifying construction processes as emergent and highly dynamic systems in an emergent setting with a complexemergent customer organization (Bertelsen and Emmitt 2005). This further explains the dynamic nature of production systems with a direct influence on value perceptions. Accordingly, with time progression, value perceptions might be revisited where any of the core project values could change to result in an added value for the project. These changes are mainly observed during design, where iterations are a common feature in the conceptual design and design development phases; trade-offs are thus made to satisfy the collective project value based on different stakeholders' input.

\section{CONCLUSION}

The value concept has been gaining momentum in construction specifically in the lean construction industry. A synthesis of the encountered topics within the literature resulted in a conceptual framework for understanding the diverse categories and attributes in regards to value generation, communication and enhancement. The framework helps in establishing a shared understanding about the concepts, factors, and aspects addressing 
value in design and construction. Certain gaps were observed on the practical level mainly regarding enhancing project value based on the collective attributes. Therefore, project management practices need to cater for the different factors within the organization structure and the mode of operation. The paper elaborated on the dynamic nature of value based on the emergent nature of the projects and their setting, and based on the interconnectedness of project attributes. Future research endeavours shall consider the proposed framework as basis for imminent proposed solutions for value measurement.

\section{REFERENCES}

Ballard, G., and Howell, G. "What kind of production is construction." Proc., Proc. 6 th Annual Conf. Int'l. Group for Lean Construction, 13-15.

Ballard, G., Koskela, L., Howell, G., and Zabelle, T. "Production system design in construction." Proc., Proceedings of the 9th annual conference of the International Group for Lean Construction.

Barima, O. J. I. J. o. P. M. (2010). "Examination of the best, analogous, competing terms to describe value in construction projects." 28(3), 195-200.

Bertelsen, S., and Emmitt, S. "The client as a complex system." Proc., 13th International Group for Lean Construction Conference: Proceedings, International Group on Lean Construction, 73.

Bourne, L., and Walker, D. H. (2005). "Visualising and mapping stakeholder influence." Management decision, 43(5), 649-660.

Cameron, B. G. (2007). "Value network modeling: a quantitative method for comparing benefit across exploration architectures." Massachusetts Institute of Technology.

Cleland, D. I., and Ireland, L. R. (2002). Project management: strategic design and implementation, McGraw-Hill.

Donaldson, T., and Preston, L. E. (1995). "The stakeholder theory of the corporation: Concepts, evidence, and implications." Academy of management Review, 20(1), 6591.

Drevland, F., Lohne, J., and Klakegg, O. J. "Ethical Dilemmas in Value Delivery: Theoretical Conditions." Proc., 25th Annual Conference of the International Group for Lean Construction, 145-152.

Drevland, F., Lohne, J., and Klakegg, O. J. (2018). "Defining An Ill-defined Concept-Nine Tenets On The Nature Of Value."

Drevland, F., and Tillmann, P. A. "Value for Whom?" Proc., 26th Annual Conference of the International Group for Lean ConstructionChennai, India, 261-270.

Emmitt, S., Sander, D., and Christoffersen, A. K. "Implementing value through lean design management." Proc., Proceedings of the 12th Int. Conference, 361-374.

Emmitt, S., Sander, D., and Christoffersen, A. K. "The value universe: defining a value based approach to lean construction." Proc., 13th International Group for Lean Construction Conference: Proceedings, Int. Group on Lean Construction, 57.

Feng, W. (2013). "Strategic management for large engineering projects: the stakeholder value network approach." Massachusetts Institute of Technology.

Fenn, P., Lowe, D., and Speck, C. (1997). "Conflict and dispute in construction." Construction Management \& Economics, 15(6), 513-518. 
Forbes, L. H., and Ahmed, S. M. (2010). Modern construction: lean project delivery and integrated practices, CRC press.

Haddadi, A., Johansen, A., and Andersen, B. (2016). "A Conceptual Framework to Enhance Value Creation in Construction Projects." Procedia Computer Science, $100,565-573$.

Haddadi, A., Johansen, A., and Bjørberg, S. (2017). "Best Value Approach (BVA): Enhancing Value Creation in Construction Projects." Business systems research journal: international journal of the Society for Advancing Business \& Information Technology (BIT), 8(2), 84-100.

Haddadi, A., Temeljotov-Salaj, A., Foss, M., and Klakegg, O. J. (2016). "The Concept of Value for Owners and Users of Buildings - A Literature Study of Value in Different Contexts." Procedia - Social and Behavioral Sciences, 226, 381-389.

Haddadi, A., Torp, O., Lohne, J., and Lædre, O. (2016). "The link between stakeholder power and value creation in construction projects." Proc. 24th Ann. Conf. of the Int'l. Group for Lean ConstructionBoston, MA, USA.

Heredia Rojas, B., Liu, L., and Lu, D. (2018). "Moderated effect of value co-creation on project performance." International Journal of Managing Projects in Business, 11(4), 854-872.

Kelly, J., and Male, S. (2003). Value management in design and construction, Routledge.

Kelly, J., Male, S., and MacPherson, S. (1993). Value management: A proposed practice manual for the briefing process, Royal Institution of Chartered Surveyors London.

Koskela, L. "Towards the theory of (lean) construction." Proc., Proceedings of the Fourth Annual Conference of the Int. Group for Lean Construction, 26-27.

Matthews, O., and Howell, G. A. J. L. c. j. (2005). "Integrated project delivery an example of relational contracting." 2(1), 46-61.

Miron, L. I. G., Kaushik, A., and Koskela, L. "Target value design: the challenge of value generation." Proc., 23rd Annual Conference of the international group for lean construction, 29-31.

Mitchell, R. K., Agle, B. R., and Wood, D. J. J. A. o. m. r. (1997). "Toward a theory of stakeholder identification and salience: Defining the principle of who and what really counts." 22(4), 853-886.

Musa, M. M., Pasquire, C., and Hurst, A. (2016). "Where lean construction and value management meet."

Ng, I. C., and Smith, L. A. (2012). "An integrative framework of value." Special issueToward a better understanding of the role of value in markets and marketing, Emerald Group Publishing Limited, 207-243.

Novak, V. M. "Value paradigm: revealing synergy between lean and sustainability." Proc., Proceedings of the 20th Conference of the International Group for Lean Construction, 51-60.

Olander, S. (2007). "Stakeholder impact analysis in construction project management." Construction management and economics, 25(3), 277-287.

Panahi, B., Moezzi, E., Preece, C. N., and Wan Zakaria, W. N. (2017). "Value conflicts and organizational commitment of internal construction stakeholders." Engineering, Construction and Architectural Management, 24(4), 554-574. 
Park, C.-S., Kim, H.-J., Park, H.-T., Goh, J.-H., and Pedro, A. (2017). "BIM-based idea bank for managing value engineering ideas." International Journal of Project Management, 35(4), 699-713.

Rozenes, S., and Cohen, Y. (2017). Handbook of Research on Strategic Alliances and Value Co-Creation in the Service Industry, IGI Global.

Salem Khalifa, A. (2004). "Customer value: a review of recent literature and an integrative configuration." Management decision, 42(5), 645-666.

Salvatierra-Garrido, J., Pasquire, C., and Miron, L. "Exploring value concept through the iglc community: Nineteen years of experience." Proc., Proceedings for the 20th Annual Conference of the Int. Group for Lean Construction, San Diego, CA.

Salvatierra-Garrido, J., and Pasquire, C. (2011). "Value theory in lean construction." Journal of Financial Management of Property and Construction, 16(1), 8-18.

Sánchez-Fernández, R., and Iniesta-Bonillo, M. Á. (2007). "The concept of perceived value: a systematic review of the research." Marketing Theory, 7(4), 427-451.

Svinicki, M. D. (2010). "A guidebook on conceptual frameworks for research in engineering education." Rigorous Research in Engineering Education, 1-53.

Thomson, D. S., Austin, S. A., Devine-Wright, H., and Mills, G. R. (2003). "Managing value and quality in design." Building Research \& Information, 31(5), 334-345.

Thyssen, M. H., Emmitt, S., Bonke, S., and Kirk-Christoffersen, A. (2010). "Facilitating client value creation in the conceptual design phase of construction projects: a workshop approach." Architectural Eng. and Design Management, 6(1), 18-30.

Tillmann, P., Ballard, G., Tzortzopoulos, P., and Formoso, C. (2012). "How integrated governance contributes to value generation: insights from an IPD case study."

Tillmann, P., Tzortzopoulos, P., Formoso, C. T., and Ballard, G. "Contributions of existing practices to pursuing value in construction projects." Proc., Proc. IGLC-21: 21st Annual Conference of the Int. Group for Lean Construction, 359-368.

Wandahl, S., and Bejder, E. "Value-based management in the supply chain of construction projects." Proc., The 11th annual conference on Lean Construction, Blacksburg. Edt.: Martinez and Formoso.

Ward, S. C., Curtis, B., and Chapman, C. B. (1991). "Objectives and performance in construction projects." Construction Management and Economics, 9(4), 343-353.

Womack, J. P., and Jones, D. T. (1996). Lean Thinking: Banish waste and Create wealth in your corporation, Free Press, New York.

Woodruff, R. B. (1997). "Customer value: The next source for competitive advantage." Journal of the Academy of Marketing Science, 25(2), 139.

Yang, J., Shen, G. Q., Ho, M., Drew, D. S., and Chan, A. P. (2009). "Exploring critical success factors for stakeholder management in construction projects." Journal of civil engineering and management, 15(4), 337-348.

Zhang, L., and El-Gohary, N. M. (2016). "Discovering Stakeholder Values for AxiologyBased Value Analysis of Building Projects." Journal of Construction Engineering and Management, 142(4), 04015095.

Zheng, X., Lu, Y., Li, Y., Le, Y., and Xiao, J. (2019). "Quantifying and visualizing value exchanges in building information modeling (BIM) projects." Automation in Construction, 99, 91-108. 